Kasteleyn, M.J., Gorter, K.J., Puffelen, A.L. van, Heijmans, M., Vos, R.C., Jansen, H., Rutten, G.E.H.M. What follow-up care and self-management support do patients with type 2 diabetes want after their first acute coronary event? A qualitative study. Primary Care Diabetes: 2014 8(3), 195-206

\begin{tabular}{|l|l|}
\hline $\begin{array}{l}\text { Postprint } \\
\text { Version }\end{array}$ & 1.0 \\
\hline Journal website & http://www.primary-care-diabetes.com/article/S1751-9918(13)00159-9/abstract \\
\hline Pubmed link & http://www.ncbi.nlm.nih.gov/pubmed/24389352 \\
\hline DOI & 10.1016/j.pcd.2013.12.001
\end{tabular}

This is a NIVEL certified Post Print, more info at http://www.nivel.eu

\title{
What follow-up care and self-management support do patients with type 2 diabetes want after their first acute coronary event? A qualitative study
}

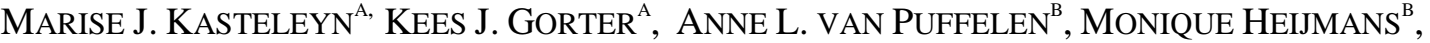 \\ RIMKE C. VOS ${ }^{\mathrm{A}}$, HANNEKE JANSEN ${ }^{\mathrm{A}}$, GUY E.H.M. RUTTEN ${ }^{\mathrm{A}}$ \\ a Julius Center for Health Sciences and Primary Care, University Medical Center Utrecht, \\ STR 6.131, P.O. Box 85500, 3508 GA Utrecht, The Netherlands \\ ${ }^{b}$ NIVEL, Netherlands Institute for Health Services Research, Utrecht, The Netherlands
}

\section{Abstract}

Aims: Despite diabetes patients' efforts to control their disease, many of them are confronted with an acute coronary event. This may evoke depressive feelings and self-management may be complicated. According to the American Diabetes Association, the transition from hospital to home after an acute coronary event (ACE) is a high-risk time for diabetes patients; it should be improved. Before developing an intervention for diabetes patients with an ACE in the period after discharge from hospital, we want to gain a detailed understanding of patients' views, perceptions and feelings in this respect.

Methods: Qualitative design. Two semi-structured focus groups were conducted with 14 T2DM patients (71\% male, aged 61-77 years) with a recent ACE. One focus group with partners (67\% male, aged 64-75 years) was held. All interviews were transcribed verbatim and analyzed by two independent researchers.

Results: Patients believed that coping with an ACE differs between patients with and without T2DM. They had problems with physical exercise, sexuality and pharmacotherapy. Patients and partners were neither satisfied with the amount of information, especially on the combination of T2DM and ACE, nor with the support offered by healthcare professionals after discharge. Participants would appreciate tailored self-management support after discharge from hospital.

Conclusions: Patients with T2DM and their partners lack tailored support after a first ACE. Our findings underpin the ADA recommendations to improve the transition from hospital to home. The results of our study will help to determine the exact content of a self-management support program delivered at home to help this specific group of patients to cope with both conditions. 
Kasteleyn, M.J., Gorter, K.J., Puffelen, A.L. van, Heijmans, M., Vos, R.C., Jansen, H., Rutten, G.E.H.M. What follow-up care and self-management support do patients with type 2 diabetes want after their first acute coronary event? A qualitative study. Primary Care Diabetes: 2014 8(3), 195-206

\section{INTRODUCTION}

Self-management by patients and their families plays a crucial role to prevent complications in type 2 diabetes (T2DM). Despite the patients' efforts to control their diabetes, they may be confronted with an acute coronary event (ACE); 19-23\% of the ACE patients have a history of diabetes [1], [2] and [3]. This confrontation may evoke depressive feelings, not only because of the physical problems, but also because people may experience a loss of control and decreased self-efficacy. In addition, self-management may be complicated, since patients also have to cope with the ACE in daily life [4] and [5]. Diabetes and cardiac disease both are associated with a decreased quality of life (QOL) [6] and [7] and the combination of diabetes and an ACE results in an even more decreased QOL from directly after discharge from the hospital up until several years later [8] and [9]. Better self-management capabilities can help patients in the period after discharge to cope with the combination of T2DM and ACE.

According to the American Diabetes Association (ADA), the transition from the hospital to home after an ACE is a high-risk time. The ADA states that diabetes discharge planning should be part of an overall discharge plan for all hospitalised patients with diabetes, which comprises a variety of aspects such as medication reconciliation, scheduling follow-up visits with the different healthcare providers and talking about medication adherence and health status [10].

Cardiac rehabilitation is widely recommended for patients with an ACE. However, benefit of the rehabilitation program on physical functioning is significantly lower in type 2 diabetes patients than in patients without diabetes [11]. Appointment adherence is lower and attrition is greater in type 2 diabetes patients as well [12]. Interventions aimed at increasing self-management capabilities can help T2DM improve functioning in daily life after discharge from hospital after an ACE. However, to the best of our knowledge, self-management support for people with the combination of these conditions in this period is scarce. Such an intervention should be tailored to the patient's wishes, and should take their preferences and preserved capacities into account [13] and [14]. Treating patients according to their preferences might improve treatment adherence and thus clinical outcomes [15]. It is not known what patients with T2DM want regarding follow-up care after an ACE. Because the partners have also to deal with the new situation, their opinions should be examined as well.

We developed an intervention to support patients with T2DM and an ACE in the period after discharge from hospital. A trained diabetes nurse will visit the patient three times at their home, starting within three weeks after discharge from hospital, to increase their self-efficacy and improve self-management. To determine the exact content of the intervention and to tailor it to the needs of this specific groups of patients, we examined in a qualitative study how T2DM patients experienced the follow-up care after an ACE, and to what extent patients with T2DM and their partners need support on several important topics. Besides, we assessed their ideas of the acceptability and efficacy of an intervention consisting of three home visits by a diabetes nurse, and we gave patients the opportunity to do suggestions for its content. 
Kasteleyn, M.J., Gorter, K.J., Puffelen, A.L. van, Heijmans, M., Vos, R.C., Jansen, H., Rutten, G.E.H.M. What follow-up care and self-management support do patients with type 2 diabetes want after their first acute coronary event? A qualitative study. Primary Care Diabetes: 2014 8(3), 195-206

This article describes the results of the focus groups. The research questions were (1) how did T2DM patients experience the follow-up care in the period after discharge from hospital after an acute coronary event? and (2) What topics should be addressed in a self-management support program after discharge from hospital for to T2DM patients and their partners? The results of the focus groups are used to determine the exact content of the above mentioned intervention.

\section{[FIGURE 1]}

\section{METHODS}

\subsection{Research design}

Semi-structured focus groups. Because of the exploratory character of the study, focus groups were conducted, providing the opportunity to explore experiences about follow-up care and opinions and expectations about a new supportive intervention. In addition, the interaction between participants in the groups led to the expression of a wider variety of opinions than might be the case if participants were interviewed individually or completed questionnaires [16]. Grounded theory underpinned the study, as it is explorative in nature and can be used to generate an hypothesis [17].

\subsection{Participants/sampling}

Two focus groups were organized with a total number of 14 patients with T2DM and a recent first ACE. All patients were asked to invite a close relative to attend a separate focus group for partners. However, only three partners participated. Reasons for not participating were travel distance, other activities/no time or no interest (Fig. 1). We conducted separate focus groups for patients and their partners to avoid unwanted influence of the absence or presence of a spouse on the patients' active participation in the group. Participants were recruited through convenience sampling via their cardiologists in two hospitals from the Northern and Western part of the Netherlands. Inclusion criteria were: (1) a history of T2DM for longer than a year;

(2) discharged from hospital after a first ACE 3-6 months before invitation; (3) sufficient physical and mental condition to attend the focus group; and (4) sufficient understanding of the Dutch language. For pragmatic reasons, the composition of the two groups was based on the distance between the place where participants were living and the venue of the focus group. We were not able to segregate focus groups by gender, type of ACE or age, but the groups did not differ on mean age and all types of ACE were represented in both groups.

\subsection{Data collection}

During the focus group, the aim and procedure of the meeting were explained to the participants. The participants were informed about the occupations of the researchers and about their interest in doing research. The experienced moderator (KG, general practitioner/assistant professor) was aware of the study objectives and led the discussion by means of a semi-structured interview guide. The observer (MK, MSc in Neurosciences, BSc in Psychology) took field notes and observed the groups. 
Kasteleyn, M.J., Gorter, K.J., Puffelen, A.L. van, Heijmans, M., Vos, R.C., Jansen, H., Rutten, G.E.H.M. What follow-up care and self-management support do patients with type 2 diabetes want after their first acute coronary event? A qualitative study. Primary Care Diabetes: 2014 8(3), 195-206

Based on literature, several topics were addressed: impact of an ACE on patients with T2DM and on their partners, general information received by the patients and their partners, physical activity, sexuality, nutrition/diet, pharmacotherapy, professional support. The moderator read out questions (Appendix 1) to which participants could express their agreement or disagreement using green and red cards. They were asked to clarify their views and perceptions and to discuss them. The questions were not pilot tested, since they were easily understandable and only used to open the discussion. When needed, the questions could have been clarified during the session. Participants were invited to bring up ideas for a suggested intervention consisting of tailored support by a diabetes nurse for patients with T2DM and a recent ACE. Each focus group session lasted two hours and was taperecorded.

\subsection{Data analysis}

Tapes were transcribed verbatim for analysis and transcripts were studied separately and independently by two researchers (MK, AP). The transcript for each focus group was analyzed using the method of Krueger [18]. MK attended the focus group, made observational notes and transcribed the tapes, thus data was familiarized. AP carefully read the transcriptions. All sections relevant to the research questions were identified. Then these sections were coded and different categories were generated to express the content of the sections from the perspective of the focus of the research. Quotes were sorted out to compare statements from participants. Catching quotes are used to illustrate the feelings and emotions of patients. The results were summarized and discussed until agreement was reached. WinMAX 98 Pro qualitative data analysis software was used to record and compare coding of transcripts. Transcripts were not returned to participants.

\section{RESULTS}

\subsection{Participants}

Of the 14 patients, 10 (71\%) were male. Their median age was 71 years (range 6177). The median duration of T2DM was 7.5 (range 1-23). For $54 \%$ of the patients, the GP was the main care provider. Of the three partners (median age 71 years, range 64-75), two were male (Table 1).

\section{[TABLE 1]}

\subsection{Patients' perspectives on follow-up care shortly after an ACE}

[TABLE 2]

Representative patients' quotes are included in Table 2.

\subsubsection{ACE has major impact on patients with T2DM}


Kasteleyn, M.J., Gorter, K.J., Puffelen, A.L. van, Heijmans, M., Vos, R.C., Jansen, H., Rutten, G.E.H.M. What follow-up care and self-management support do patients with type 2 diabetes want after their first acute coronary event? A qualitative study. Primary Care Diabetes: 2014 8(3), 195-206

When discussing the combination of T2DM and ACE, there were differences in the type of concerns patients expressed ('Yes, I'm really afraid that the diabetes makes the heart problem worse. I'm scared to death.' (male, 61 years)). Some were mainly worried about their diabetes, whereas others were mainly worried about their ACE. Furthermore, they had to cope with the ACE in daily life, which was impaired by the T2DM according to the participants.

Six patients believed that coping with an ACE differs between patients with and without T2DM, since the diabetes is an additional risk factor for the ACE and also affects other organs. On the other hand, six patients thought that coping with an ACE does not differ between patients with and without T2DM. Furthermore, participants thought that patients with T2DM and an ACE tend to adopt healthier lifestyles, compared to ACE patients without diabetes. One of the patients stated he was more prepared for an ACE, due to the fact that he already had T2DM (quote 1.1). The four patients who told that they experienced difficulties coping with more than one disease, not only had to cope with T2DM and an ACE, but also with several other complications, such as peripheral artery disease (quote 1.2).

The partners had their own ideas about the coping behavior of the patients. One confirmed that his partner with T2DM had 'too many complications', making coping more difficult. Another thought that there is no difference in coping between ACE patients with or without T2DM, which was in contrast to her partner. Also on other topics there were striking differences between the patient's and the partner's statements, indicating that partners are not always aware of the feelings of the patients (Table 3).

\section{[TABLE 3]}

\subsubsection{Information on the combination of T2DM and an ACE is lacking}

Although participants stated that they were given a lot of information after the ACE, both orally and by leaflets, nine patients and three partners reported some lack of information. For example, some received enough information about the heart problem, but not about the heart problem in combination with the diabetes (quote 2.1). Since patients had to cope with the combination of the two conditions in daily life, they had the feeling additional information could have been useful. One of the participants stated to have received contradicting information from his diabetes nurse and general practitioner (GP), making life more difficult ('There is enough information, but sometimes I get conflicting information. The diabetes nurse says one thing, but the general practitioner says something else. So the information is not correct, that makes it complicated.' (male, 64 years)). Three participants had expected more information from the healthcare professionals, for example about the combination of T2DM and an ACE (quote 2.2). The lack of information and contradicting information induced uncertainties for the patients.

Only three patients were satisfied with the amount of information they received after discharge from hospital. Two patients had searched for information themselves. Remarkably, two patients and two partners did not know that diabetes is a risk factor for an ACE (quote 2.3). 
Kasteleyn, M.J., Gorter, K.J., Puffelen, A.L. van, Heijmans, M., Vos, R.C., Jansen, H., Rutten, G.E.H.M. What follow-up care and self-management support do patients with type 2 diabetes want after their first acute coronary event? A qualitative study. Primary Care Diabetes: 2014 8(3), 195-206

\subsubsection{Confusion regarding physical exercise recommendations}

Patients with an angioplasty did not receive physiotherapy or cardiac rehabilitation, in contrast to patients with a bypass or a MI. For half of the patients, with different types of ACEs, and for two partners, it was not clear what to do regarding physical exercise (quote 3.1), resulting in insecurity and anxiety. One patient reported that he knew himself what to do. Some patients had other physical problems as well, such as back and hip problems. One of them stated to be content that the revalidation for her ACE and hip had been combined. Only two participants mentioned a cardiac rehabilitation course, and both said that it was not tailored to their level of fitness (quote 3.2). Furthermore, they had to wait too long for the course to start (quote 3.3).

\subsubsection{Recommendations on sexual activity are lacking}

Several patients did experience a lot of problems regarding sexuality, both physically and mentally. Half of the patients reported nothing had been asked or discussed regarding sexuality in the period after their ACE; they would like to have received more information on this topic. T2DM patients may already have difficulties regarding sexuality, and the ACE makes it even more complicated ('In my opinion, you already have diabetes, which causes a lot of problems, and then you think, 'How do I deal with this?'. It is allowed to have sex, but it is so difficult all together. When you have diabetes for a very long time, and you use insulin, you have so many physical discomforts. And then you have the heart on top of it, then you think, hello, how how... If sexuality were not an issue anymore, then it would have been easier.

But it is not.' (female, 71 years)). Only one patient reported that sexuality was discussed in the hospital (quote 4.1), two mentioned that information about sexuality was given as part of the written take home information. In addition, one patient looked it up for herself.

One of the partners said that his wife received information on sexuality, although she stated that sexuality was not discussed. In addition, the partner who said sexuality was discussed with his wife did not know how to deal with sexuality after discharge from hospital.

\subsubsection{Minimal problems with nutrition/diet}

Nutrition was not problematic. Most participants already had a diet for their diabetes, which was sufficient for their ACE as well (quote 5.1). Four patients reported that they heard nothing from their cardiologist about diet. One patient was given different advices from the GP and the diabetes nurse. Therefore, he figured out with his partner what to do with nutrition. Three subjects searched for information themselves. The partners agreed with the patients, nutrition was not problematic.

\subsubsection{Difficulties in coping with the amount of medication and the adverse effects}

In contrast to nutrition, medication was problematic. Especially in patients with the combination of T2DM and ACE this is important, since they receive medications for both conditions. Half of the patients reported lack of information about pharmacotherapy (quote 6.1). For example, they did not know the effects of the medication. In addition, six patients complained about side effects. Five patients 
Kasteleyn, M.J., Gorter, K.J., Puffelen, A.L. van, Heijmans, M., Vos, R.C., Jansen, H., Rutten, G.E.H.M. What follow-up care and self-management support do patients with type 2 diabetes want after their first acute coronary event? A qualitative study. Primary Care Diabetes: 2014 8(3), 195-206

were frustrated or distressed by the amount of medication they had to take ('I have to take 13 pills a day, for the diabetes and the heart, which takes quite a lot. I feel like a totally different person. I don't feel like myself anymore. And there is no one I can talk about this.' (male, 69 years)).

Only one patient had no problems with medication. Six patients reported that they had received some information about medication in a leaflet as part of the take home information from the hospital (quote 6.2).

One of the partners supported the patients' view that the amount of medication was problematic and frustrating. However, one other partner said that there was no problem, although his partner with diabetes had difficulties in coping with the amount of tablets. Furthermore, three patients and two partners visited their pharmacist several times to get more clarity about the medicines. They appreciated these visits very much.

\subsubsection{Dissatisfaction about support and accessibility of medical professionals}

There was discussion about the support from healthcare professionals. This is especially important in T2DM since they have to deal with a variety of health care professionals. Several patients reported difficulties on this topic. Although they undertook action themselves, three of them had difficulties in contacting the GP, which makes them frustrated. For example, they would have liked to visit the GP, but the practice assistants were not cooperative (quote 7.1). Another participant was not sure for which problem he had to contact which professional. In addition, one of the partners said to forget some questions during the consultation, due to time pressure (quote 7.2). Four patients reported no problems and said they could contact the GP when needed. Most participants reported they would have liked to have the information on all topics earlier in the hospital or shortly after discharge from the GP. In addition, most were disappointed about the amount of empathy they received from healthcare professionals and expected more support ('If the GP had said 'Gosh girl, that is a whole bag full of medicines you have', a little sympathy.' (female, 71 years)).

\subsubsection{Partners are worried and lack adequate information}

Four patients stated they felt supported by their partners in coping with their ACE and T2DM, although their partner had difficulties with the new situation as well. Furthermore, most patients and partners agreed that the partners were worried about the situation of the patients ('I think, it is especially hard for the partners, since they worry the most'. (male, 61 years)), resulting in overprotective behavior. According to the patients, overprotection of the partners made coping more difficult for the patients (quote 8.1). In addition, two partners emphasized they were dependent on the patient which information they received (quote 8.2). They would like to have objective information themselves from the healthcare professionals. Patients also indicated that it is difficult when partners are not well informed.

\subsubsection{Patients 'perspectives on self-management support}


Kasteleyn, M.J., Gorter, K.J., Puffelen, A.L. van, Heijmans, M., Vos, R.C., Jansen, H., Rutten, G.E.H.M. What follow-up care and self-management support do patients with type 2 diabetes want after their first acute coronary event? A qualitative study. Primary Care Diabetes: 2014 8(3), 195-206

At the end of the session, a draft self-management support program for patients with T2DM and a first ACE was discussed. According to the draft, the intervention would consist of three home visits by a diabetes nurse. Patients and partners were invited to bring up suggestions for this program. Almost all were positive about tailored selfmanagement support and mentioned several topics that were important in the period shortly after discharge from the hospital. For example, three of them mentioned pharmacotherapy as an important topic; they missed support in coping with the large amount of medications (due to the combination of T2DM and ACE) and the side effects ('I received a list with all medication I needed to take; my wife picked them up at our local pharmacy. She came home with that whole pack of medicine, but I already had a whole bunch of medicine I needed to take. I cried.' (male, 69 years)). In addition, four patients stated that they would take the opportunity to ask questions that arise over time to the diabetes nurse. Another important benefit of selfmanagement programs mentioned by the patients is the feeling to be supported and understood (quote 9.1).

According to six patients such a self-management program consisting of home visits is not only beneficial for the patient, but also for the partner or other family members (quote 9.2). For them, coping with the new situation requires adaptations as well. For seven patients, another important advantage of home visits would be that they can be tailored to the patient's specific situation (quote 9.3).

However, some patients were suspicious about the skills of a diabetes nurse and emphasized that it would be necessary to train the nurses on heart problems. Two emphasized the importance to feel comfortable with the nurse. Besides, three patients were suspicious about the feasibility of such a program, because they question whether enough healthcare professionals would be available to offer such a program. The partners thought it would be helpful and mentioned the same benefits as the patients. The home situation would be a safe environment to discuss problematic topics.

\section{DISCUSSION}

Half of the patients with T2DM considered themselves to be a specific group of ACE patients. They have to cope with several diseases at the same time: T2DM, the ACE and other complications. This makes coping with the occurrence of an ACE more burdensome. A lot of general information may already have been given after an ACE about the ACE only, but patients with diabetes reported lack of information on the combination of the ACE and T2DM, resulting in uncertainties. They missed support and had difficulties in coping with the two concomitant diseases. Furthermore, there were uncertainties regarding physical exercise. Cardiac rehabilitation was not tailored to the individual levels of fitness. Coping with problems regarding sexuality seemed to be problematic as well. Handling the large amount of tablets and possible side effects was considered quite problematic and frustrating. In contrast, most patients had no difficulties or worries about nutrition. Several partners were over concerned and overprotective. Overall, patients were not satisfied with the current follow-up care, resulting in negative feelings, frustrations and uncertainties. Both patients with T2DM and their partners were positive about a self-management support program delivered shortly after discharge from hospital. Previous research 
Kasteleyn, M.J., Gorter, K.J., Puffelen, A.L. van, Heijmans, M., Vos, R.C., Jansen, H., Rutten, G.E.H.M. What follow-up care and self-management support do patients with type 2 diabetes want after their first acute coronary event? A qualitative study. Primary Care Diabetes: 2014 8(3), 195-206

showed that patients with diabetes have difficulties regarding self-management, especially when they have to deal with complications [4] and [5]. For example, they reported that important information was lacking [19] or information was vague and too general [20]. This is in line with our study, where several patients reported problems regarding information provision after discharge, especially on the combination of the two conditions. Advices from different health-care professionals could result in conflicting information [20], which was also reported by patients in our study. In addition, from our study it became evident that patients are confused by confliction information, which is considered problematic. These studies did not focus specifically on the combination of type 2 diabetes and ACE in the period after discharge from hospital.

Previous studies on cardiac rehabilitation showed that it is not well implemented in current clinical practice, although widely recommended for patients with an ACE. In the Netherlands, a minority (28.5-8.7\%, depending on type of ACE) of the ACE patients receives cardiac rehabilitation [21]. The focus groups demonstrated that patients worried about physical exercise since they were not sure whether they were allowed to do the former exercises after their ACE. In addition, they were not satisfied with the cardiac rehabilitation and they were upset since waiting lists were long. This is an indication that special attention should be given to ACE patients with type 2 diabetes regarding physical exercise.

Healthcare professionals mostly do not discuss sexual concerns with hospitalised patients [22] and [23]. Reported reasons for not discussing sexual issues with heart patients are older age of the patient, risk of increasing cardiac symptoms, fear of sudden cardiac death and raising patient's anxiety levels and lack of training [24] and [25]. This is in line with our results; in spite of the patients' need to discuss sexuality, it was almost never mentioned by any health care provider. This topic is especially important in T2DM patients, since they have experienced difficulties regarding sexuality due to the diabetes which makes an ACE on top of that even more burdensome. Furthermore, participants were feeling pessimistic about this. In our focus groups, several concerns regarding medical treatment were mentioned. In patients with the combination of T2DM and ACE this is even more difficult than in ACE patients without diabetes, since patients receive medications for both conditions. People felt frustrated about the amount of pills they had to take and the adverse effects. Previous studies showed that medication non-adherence is prevalent among patients with diabetes and cardiovascular disease and is associated with adverse outcomes [26] and [27]. Mann et al. [28] found that predictors of poor adherence are maladaptive illness perceptions, worries about side effects and lack of self-efficacy. These predictors are modifiable [29] and [30] and should be addressed in interventions.

Patients in the focus groups stated that their partners were more worried than themselves. This is confirmed by the partners. Both considered that as problematic and indicated that it has a negative influence on their relation. Overprotection by the partner may be associated with higher levels of distress in patients in several chronic diseases [31]. Therefore, partners should be involved in supportive programs as well. A previous study showed that patients are in need of structured follow-up after discharge, and that a one-size-fits all approach is not suitable for most of them [20]. The participants in our study also indicated that they consider themselves a specific 
Kasteleyn, M.J., Gorter, K.J., Puffelen, A.L. van, Heijmans, M., Vos, R.C., Jansen, H., Rutten, G.E.H.M. What follow-up care and self-management support do patients with type 2 diabetes want after their first acute coronary event? A qualitative study. Primary Care Diabetes: 2014 8(3), 195-206

group of patients, for which the usual follow-up care is not sufficient. The American Diabetes Association (ADA) [10] also recommends structured follow-up care after discharge. Interventions are needed that focus on all topics addressed above and should be tailored to the individual needs of the patient.

The small sample size of this study is a potential limitation that could reduce the generalizability of the results and the issues that arise. In focus group research the amount of sessions needed depends on whether an additional session provides new information [18]. In most studies two sessions are sufficient, and a third does barely add something new. Data saturation was not assessed. We planned in advance to conduct two focus groups for patients and one for the partners. The information given by the partners was mostly complementary to the information given by the participants. We think their opinions are valuable and should be included. The consistency between the groups and the agreement with the literature suggests that the inferences are applicable to the majority of the patients with T2DM and an ACE. Taken the above into account, and the fact that findings of this study are exploratory with the aim to generate hypotheses, we believe that additional focus groups would have had no added value. To make any strong conclusions about follow-up care and self-management support for T2DM patients with an ACE and their partners, our findings require further confirmatory evidence. Therefore, we will conduct a randomized controlled trial to evaluate the efficacy of a supportive intervention for these patients and their partners which is based on the results of the focus groups.

\section{CONCLUSION}

Patients with T2DM and their partners are lacking tailored support after a first ACE. These findings underpin the ADA recommendation to improve the transition from hospital to home. Interventions should be tested to fill this gap. The results of our study will help to determine the exact content of a self-management support program delivered at home to help this specific group of patients to cope with both conditions.

\section{CONFLICTS OF INTERESTS}

The authors state that they have no conflict of interest.

\section{FUNDING}

This study is funded by the Dutch Diabetes Research Foundation (no. 2009.70). The Dutch Diabetes Research Foundation critically reviewed the design of the study and is updated yearly on the progress of the project and relevant changes.

\section{AUTHORS' CONTRIBUTIONS}

GR is the principle investigator of the study. GR, KG and MK were involved in designing the study. MK and KG conducted the focus groups. MK and AP analyzed the transcripts of the focus groups. All authors have corrected draft versions and approved the final manuscript. 
Kasteleyn, M.J., Gorter, K.J., Puffelen, A.L. van, Heijmans, M., Vos, R.C., Jansen, H., Rutten, G.E.H.M. What follow-up care and self-management support do patients with type 2 diabetes want after their first acute coronary event? A qualitative study. Primary Care Diabetes: 2014 8(3), 195-206

\section{APPENDIX A. STRUCTURE OF THE FOCUS GROUP SESSIONS}

\begin{tabular}{|c|c|}
\hline & $\begin{array}{l}\text { Do you think there is a difference in the way people with diabetes cope } \\
\text { with a heart problem compared to people without diabetes? } \\
\text { Why do you think so? }\end{array}$ \\
\hline & $\begin{array}{l}\text { Do you think there is enough information available for people with } \\
\text { diabetes and a heart problem? } \\
\text { Can you explain this? }\end{array}$ \\
\hline & $\begin{array}{l}\text { Was it clear to you which things you could or could not eat/which diet } \\
\text { you had to follow after the heart problem. } \\
\text { If not, can you explain this in more detail? }\end{array}$ \\
\hline & $\begin{array}{l}\text { Was it clear to you to what extent you could be physically active? Would } \\
\text { you have liked it if you had received more support/information in the } \\
\text { period after discharge from the hospital? } \\
\text { If yes, from who? }\end{array}$ \\
\hline & $\begin{array}{l}\text { Was it clear to you to what extent you could be sexually active? Would } \\
\text { you have liked it if you had received more support/information in the } \\
\text { period after discharge from the hospital? }\end{array}$ \\
\hline & $\begin{array}{l}\text { My medicine use became too complicated after the heart problem. Do } \\
\text { you agree or disagree? Would you have liked it if you had received more } \\
\text { support with this in the period after discharge from the hospital? } \\
\text { If yes, from who? }\end{array}$ \\
\hline Q7: & Was it clear to you for which problem you had to visit which doctor? \\
\hline & $\begin{array}{l}\text { I would have liked it if I was visited at home after my heart problem by a } \\
\text { nurse who was there for me and could help me with all sorts of problems } \\
\text { which I encountered. Do you agree or disagree? } \\
\text { Can you explain this? } \\
\text { How should such visits look like? }\end{array}$ \\
\hline & $\begin{array}{l}\text { To which extent should you have liked it if your partner/close relatives } \\
\text { was involved in the after-care? How canthisbedone? }\end{array}$ \\
\hline
\end{tabular}


Kasteleyn, M.J., Gorter, K.J., Puffelen, A.L. van, Heijmans, M., Vos, R.C., Jansen, H., Rutten, G.E.H.M. What follow-up care and self-management support do patients with type 2 diabetes want after their first acute coronary event? A qualitative study. Primary Care Diabetes: 2014 8(3), 195-206

APPENDIX B. CONSOLIDATED CRITERIA FOR REPORTING QUALITATIVE RESEARCH (COREQ): A 32-ITEM CHECKLIST FOR INTERVIEWS AND FOCUS GROUPS

\begin{tabular}{|c|c|c|c|}
\hline \multicolumn{4}{|c|}{ Domain 1: Research team and reflexivity } \\
\hline \multicolumn{4}{|c|}{ Personal characteristics } \\
\hline 1. & Interviewer/facilitator & $\begin{array}{l}\text { Which author/s } \\
\text { conducted the interview } \\
\text { or focus group? }\end{array}$ & $\begin{array}{l}\text { KG(moderator) and MK } \\
\text { (observer) }\end{array}$ \\
\hline 2. & Credentials & $\begin{array}{l}\text { What were the } \\
\text { researcher's credentials? } \\
\text { E.g. } P h D, M D\end{array}$ & $\begin{array}{l}\text { KG: MD, PhD } \\
\text { MK: MSc in } \\
\text { Neurosciences; BSc in } \\
\text { Psychology }\end{array}$ \\
\hline 3. & Occupation & $\begin{array}{l}\text { What was their } \\
\text { occupation at the time of } \\
\text { the study? }\end{array}$ & $\begin{array}{l}\text { KG: } \\
* \text { Assistant professor at } \\
\text { the Julius Center, UMC } \\
\text { Utrecht } \\
* \text { General Practitioner at } \\
\text { the time of the study } \\
\text { MK: } \\
\text { *PhD student at the Julius } \\
\text { Center, UMC Utrecht }\end{array}$ \\
\hline 4. & Gender & $\begin{array}{l}\text { Was the researcher male } \\
\text { or female? }\end{array}$ & KG: male \\
\hline & & & MK: female \\
\hline 5. & $\begin{array}{l}\text { Experience and } \\
\text { training }\end{array}$ & $\begin{array}{l}\text { What experience or } \\
\text { training did the } \\
\text { researcher have? }\end{array}$ & $\begin{array}{l}\text { KG: Previous qualitative } \\
\text { projects } \\
\text { MK: Training in } \\
\text { qualitative data analysis. } \\
\text { BSc in psychology. }\end{array}$ \\
\hline \multicolumn{4}{|c|}{ Relationship with participants } \\
\hline 6. & $\begin{array}{l}\text { Relationship } \\
\text { established }\end{array}$ & $\begin{array}{l}\text { Was a relationship } \\
\text { established prior to } \\
\text { study commencement? }\end{array}$ & No \\
\hline 7. & $\begin{array}{l}\text { Participant } \\
\text { knowledge of the } \\
\text { interviewer }\end{array}$ & $\begin{array}{l}\text { What did the } \\
\text { participants know about } \\
\text { the researcher? e.g. } \\
\text { personal goals, reasons } \\
\text { for doing the research }\end{array}$ & $\begin{array}{l}\text { Occupation at the time of } \\
\text { study and personal interest } \\
\text { in doing research were } \\
\text { described prior to the } \\
\text { focus groups }\end{array}$ \\
\hline 8. & $\begin{array}{l}\text { Interviewer } \\
\text { characteristics }\end{array}$ & $\begin{array}{l}\text { What characteristics } \\
\text { were reported about the } \\
\text { interviewer/facilitator? } \\
\text { e.g. Bias, assumptions, } \\
\text { reasons and interests in } \\
\text { the research topic }\end{array}$ & $\begin{array}{l}\text { Research interests were } \\
\text { reported }\end{array}$ \\
\hline
\end{tabular}


Kasteleyn, M.J., Gorter, K.J., Puffelen, A.L. van, Heijmans, M., Vos, R.C., Jansen, H., Rutten, G.E.H.M. What follow-up care and self-management support do patients with type 2 diabetes want after their first acute coronary event? A qualitative study. Primary Care Diabetes: 2014

\begin{tabular}{|c|c|c|}
\hline \multicolumn{3}{|l|}{ Domain 2: study design } \\
\hline \multicolumn{3}{|l|}{ Theoretical framework } \\
\hline $\begin{array}{l}\text { 9. } \begin{array}{l}\text { Methodological } \\
\text { orientation and } \\
\text { Theory }\end{array} \\
\end{array}$ & $\begin{array}{l}\text { What methodological } \\
\text { orientation was stated to } \\
\text { underpin the study? e.g. } \\
\text { grounded theory, } \\
\text { discourse analysis, } \\
\text { ethnography, } \\
\text { phenomenology, content } \\
\text { analysis }\end{array}$ & $\begin{array}{l}\text { Grounded theory. The aim } \\
\text { of the study was to } \\
\text { explore opinions of } \\
\text { T2DM patients on follow- } \\
\text { up care after an ACE. The } \\
\text { focus groups are used to } \\
\text { design an intervention to } \\
\text { support T2DM after } \\
\text { discharge from hospital } \\
\text { after an ACE. }\end{array}$ \\
\hline 10. Sampling & $\begin{array}{l}\text { How were participants } \\
\text { selected? e.g. purposive, } \\
\text { convenience, } \\
\text { consecutive, snowball }\end{array}$ & $\begin{array}{l}\text { Convenience sampling. } \\
\text { Patients with T2DM and } \\
\text { ACE were invited to } \\
\text { participate. }\end{array}$ \\
\hline 11. Method of approach & $\begin{array}{l}\text { How were participants } \\
\text { approached? e.g. face- } \\
\text { to-face, telephone, mail, } \\
\text { email }\end{array}$ & By telephone \\
\hline 12. Sample size & $\begin{array}{l}\text { How many participants } \\
\text { were in the study? }\end{array}$ & 14 \\
\hline 13. Non-participation & $\begin{array}{l}\text { How many people } \\
\text { refused to participate or } \\
\text { dropped out? Reasons? }\end{array}$ & $\begin{array}{l}30 \text { patients were invited to } \\
\text { participate. } 10 \text { patients } \\
\text { had no interest (reasons: } \\
\text { no time, no interest in } \\
\text { research, not able to attend } \\
\text { the focus groups). Of the } \\
20 \text { interested patients, } 3 \\
\text { were not able to attend the } \\
\text { focus group because of } \\
\text { other appointments on that } \\
\text { day/time. } 17 \text { patients } \\
\text { registered to the focus } \\
\text { group; } 3 \text { did not show up } \\
\text { (reasons family } \\
\text { circumstances/illness) }\end{array}$ \\
\hline & & $\begin{array}{l}\text { All interested patients ( } n= \\
\text { 20) were asked to invite a } \\
\text { partner/close relative to } \\
\text { participate to the focus } \\
\text { group. } 10 \text { were interested }\end{array}$ \\
\hline
\end{tabular}




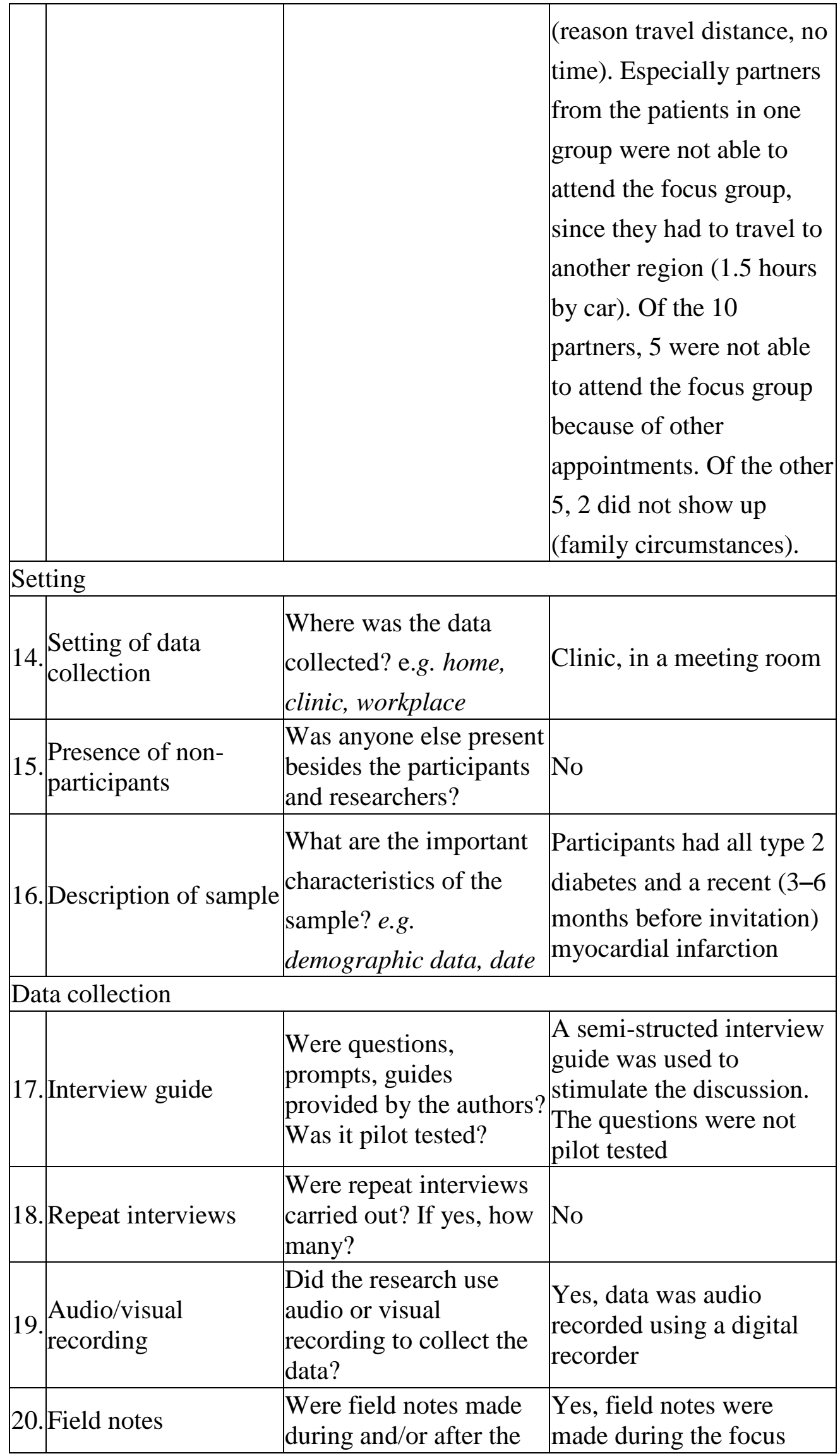


Kasteleyn, M.J., Gorter, K.J., Puffelen, A.L. van, Heijmans, M., Vos, R.C., Jansen, H., Rutten, G.E.H.M. What follow-up care and self-management support do patients with type 2 diabetes want after their first acute coronary event? A qualitative study. Primary Care Diabetes: 2014

\begin{tabular}{|c|c|c|c|}
\hline & & $\begin{array}{l}\text { interview or focus } \\
\text { group? }\end{array}$ & group \\
\hline & 1.Duration & $\begin{array}{l}\text { What was the duration } \\
\text { of the interviews or } \\
\text { focus group? }\end{array}$ & $\begin{array}{l}\text { Duration of each focus } \\
\text { group was two hours }\end{array}$ \\
\hline & 2. Data saturation & $\begin{array}{l}\text { Was data saturation } \\
\text { discussed? }\end{array}$ & $\begin{array}{l}\text { Data saturation was not } \\
\text { discussed. We planned in } \\
\text { advance to conduct two } \\
\text { focus groups for patients } \\
\text { and one for the partners. }\end{array}$ \\
\hline & 3. Transcripts returned & $\begin{array}{l}\text { Were transcripts } \\
\text { returned to participants } \\
\text { for comment and/or } \\
\text { correction? }\end{array}$ & No \\
\hline \multicolumn{4}{|c|}{ Domain 3: analysis and findings } \\
\hline \multicolumn{4}{|c|}{ Data analysis } \\
\hline & $\begin{array}{l}\text { 4. Number of data } \\
\text { coders }\end{array}$ & $\begin{array}{l}\text { How many data coders } \\
\text { coded the data? }\end{array}$ & Two \\
\hline & $\begin{array}{l}\text { Description of the } \\
\text { coding tree }\end{array}$ & \begin{tabular}{|l|} 
Did authors provide a \\
description of the coding \\
tree?
\end{tabular} & No \\
\hline & 5. Derivation of themes & $\begin{array}{l}\text { Were themes identified } \\
\text { in advance or derived } \\
\text { from the data? }\end{array}$ & $\begin{array}{l}\text { Main topics to discuss } \\
\text { were determined in } \\
\text { advance. However, after } \\
\text { summing up these topics } \\
\text { participants were } \\
\text { explicitly stimulated to } \\
\text { bring additional topics } \\
\text { forward. The 'open' } \\
\text { character of the session } \\
\text { was emphasized. }\end{array}$ \\
\hline & 7. Software & \begin{tabular}{|l|} 
What software, if \\
applicable, was used to \\
manage the data?
\end{tabular} & WinMax 98 Pro \\
\hline & 3. Participant checking & $\begin{array}{l}\text { Did participants provide } \\
\text { feedback on the } \\
\text { findings? }\end{array}$ & No \\
\hline \multicolumn{4}{|c|}{ Reporting } \\
\hline & 9. Quotations presented & $\begin{array}{l}\text { Were participant } \\
\text { quotations presented to } \\
\text { illustrate the } \\
\text { themes/findings? Was } \\
\text { each quotation } \\
\text { identified? e.g. }\end{array}$ & Yes \\
\hline
\end{tabular}


Kasteleyn, M.J., Gorter, K.J., Puffelen, A.L. van, Heijmans, M., Vos, R.C., Jansen, H., Rutten, G.E.H.M. What follow-up care and self-management support do patients with type 2 diabetes want after their first acute coronary event? A qualitative study. Primary Care Diabetes: 2014 8(3), 195-206

\begin{tabular}{|l|l|l|l|}
\hline 30. & $\begin{array}{l}\text { participant number } \\
\text { Data and findings } \\
\text { consistent }\end{array}$ & $\begin{array}{l}\text { Was there consistency } \\
\text { between the data } \\
\text { presented and the } \\
\text { findings? }\end{array}$ & Yes \\
\hline 31. & $\begin{array}{l}\text { Clarity of major } \\
\text { themes }\end{array}$ & $\begin{array}{l}\text { Were major themes } \\
\text { clearly presented in the } \\
\text { findings? }\end{array}$ & Yes \\
\hline 32. & $\begin{array}{l}\text { Clarity of minor } \\
\text { themes }\end{array}$ & $\begin{array}{l}\text { Is there a description of } \\
\text { diverse cases or } \\
\text { discussion of minor } \\
\text { themes? }\end{array}$ & Yes \\
\hline
\end{tabular}


Kasteleyn, M.J., Gorter, K.J., Puffelen, A.L. van, Heijmans, M., Vos, R.C., Jansen, H., Rutten, G.E.H.M. What follow-up care and self-management support do patients with type 2 diabetes want after their first acute coronary event? A qualitative study. Primary Care Diabetes: 2014 8(3), 195-206

\section{REFERENCES}

[1] K. Franklin, R.J. Goldberg, F. Spencer, W. Klein, A. Budaj, D. Brieger et al. Implications of diabetes in patients with acute coronary syndromes. The Global Registry of Acute Coronary Events Arch. Intern. Med., 164 (13) (2004), pp. 1457-1463

[2] D. Hasdai, S. Behar, L. Wallentin, N. Danchin, A.K. Gitt, E. Boersma et al. A prospective survey of the characteristics: treatments and outcomes of patients with acute coronary syndromes in Europe and the Mediterranean basin: the Euro Heart Survey of Acute Coronary Syndromes (Euro Heart Survey ACS) Eur. Heart J., 23 (15) (2002), pp. 11901201

[3] K. Malmberg, S. Yusuf, H.C. Gerstein, J. Brown, F. Zhao, D. Hunt et al. Impact of diabetes on long-term prognosis in patients with unstable angina and non-Q-wave myocardial infarction: results of the OASIS (Organization to Assess Strategies for Ischemic Syndromes) Registry Circulation, 102 (9) (2000), pp. 1014-1019

[4] J.T. Coffey, M. Brandle, H. Zhou, D. Marriott, R. Burke, B.P. Tabaei et al. Valuing healthrelated quality of life in diabetes Diabetes Care, 25 (12) (2002), pp. 2238-2243

[5] K.W. Watkins, C.M. Connell, J.T. Fitzgerald, L. Klem, T. Hickey, B. Ingersoll-Dayton Effect of adults' self-regulation of diabetes on quality-of-life outcomes Diabetes Care, 23 (10) (2000), pp. 1511-1515

[6] C.A. Beck, L. Joseph, P. Belisle, L. Pilote Predictors of quality of life 6 months and 1 year after acute myocardial infarction Am. Heart J., 142 (2) (2001), pp. 271-279

[7] C.H. van Jaarsveld, R. Sanderman, I. Miedema, A.V. Ranchor, G.I. Kempen Changes in health-related quality of life in older patients with acute myocardial infarction or congestive heart failure: a prospective study J. Am. Geriatr. Soc., 49 (8) (2001), pp. 1052-1058

[8] I. Uchmanowicz, K. Loboz-Grudzien, B. Jankowska-Polanska, L. Sokalski Influence of diabetes on health-related quality of life results in patients with acute coronary syndrome treated with coronary angioplasty Acta Diabetol., 50 (2) (2011), pp. 217-225

[9] P.R. Wermeling, K.J. Gorter, H.F. van Stel, G.E. Rutten Both cardiovascular and noncardiovascular comorbidity are related to health status in well-controlled type 2 diabetes patients: a cross-sectional analysis Cardiovasc. Diabetol., 11 (2012), p. 121

[10] Introduction: The American Diabetes Association's (ADA) evidence-based practice guidelines, standards, and related recommendations and documents for diabetes care Diabetes Care, 35 (Suppl 1) (2012), pp. S1-S2

[11] B. Verges, B. Patois-Verges, M. Cohen, B. Lucas, C. Galland-Jos, J.M. Casillas Effects of cardiac rehabilitation on exercise capacity in Type 2 diabetic patients with coronary artery disease Diabet. Med., 21 (8) (2004), pp. 889-895

[12] J.K. Miketic, M. Hravnak, C.S. Stilley, R.J. Robertson, S.M. Sereika Factors influencing the outcomes of patients with both coronary artery disease and diabetes enrolled in standard cardiac rehabilitation programs: a literature review J. Cardiovasc. Nurs., 26 (3) (2011), pp. 210-217

[13] A. Coulter Do patients want a choice and does it work? BMJ, 341 (2010), p. c4989

[14] K.J. Gorter, G.H. Tuytel, L. de Jr., J.J. van der Bijl, J.M. Bensing, G.E. Rutten Preferences and opinions of patients with Type 2 diabetes on education and self-care: a cross-sectional survey Diabet. Med., 27 (1) (2010), pp. 85-91

[15] M.L. Parchman, J.E. Zeber, R.F. Palmer Participatory decision making, patient activation, medication adherence, and intermediate clinical outcomes in type 2 diabetes: a STARNet study Ann. Fam. Med., 8 (5) (2010), pp. 410-417

[16] J. Kitzinger Qualitative research. Introducing focus groups BMJ, 311 (7000) (1995), pp. 299-302 
Kasteleyn, M.J., Gorter, K.J., Puffelen, A.L. van, Heijmans, M., Vos, R.C., Jansen, H., Rutten, G.E.H.M. What follow-up care and self-management support do patients with type 2 diabetes want after their first acute coronary event? A qualitative study. Primary Care Diabetes: 2014 8(3), 195-206

[17] B.G. Glaser, A.L. Strauss The Discovery of Grounded Theory: Strategies for Qualitative Research Aldine, Chicago (1967)

[18] R.A. Krueger Analysing and Reporting Focus Groups Results Sage Publications, Thousand Oaks, CA (1998)

[19] D.E. Holland, P. Mistiaen, K.H. Bowles Problems and unmet needs of patients discharged home to self-care Prof. Case Manag., 16 (5) (2011), pp. 240-250

[20] A. McMurray, P. Johnson, M. Wallis, E. Patterson, S. Griffiths General surgical patients' perspectives of the adequacy and appropriateness of discharge planning to facilitate health decision-making at home J. Clin. Nurs., 16 (9) (2007), pp. 1602-1609

[21] M. Van Engen-Verheul, H. de Vries, H. Kemps, R. Kraaijenhagen, N. de Keizer, N. Peek Cardiac rehabilitation uptake and its determinants in the Netherlands Eur. J. Prev. Cardiol.

(2012), pp. 1-8

[22] N. Saunamaki, M. Andersson, M. Engstrom Discussing sexuality with patients: nurses' attitudes and beliefs J. Adv. Nurs., 66 (6) (2010), pp. 1308-1316

[23] E. Steinke, P. Patterson-Midgley Sexual counseling following acute myocardial infarction Clin. Nurs. Res., 5 (4) (1996), pp. 462-472

[24] T. Hoekstra, I. Lesman-Leegte, M.F. Couperus, R. Sanderman, T. Jaarsma What keeps nurses from the sexual counseling of patients with heart failure? Heart Lung, 41 (5) (2012), pp. 492-499

[25] T. Jaarsma, A. Stromberg, B. Fridlund, G.S. De, J. Martensson, P. Moons et al. Sexual counselling of cardiac patients: nurses' perception of practice, responsibility and confidence Eur. J. Cardiovasc. Nurs., 9 (1) (2010), pp. 24-29

[26] P.M. Ho, D.J. Magid, F.A. Masoudi, D.L. McClure, J.S. Rumsfeld Adherence to cardioprotective medications and mortality among patients with diabetes and ische mic heart disease BMC Cardiovasc. Disord., 6 (2006), p. 48

[27] K.J. Lipska, Y. Wang, M. Kosiborod, F.A. Masoudi, E.P. Havranek, H.M. Krumholz et al. Discontinuation of antihyperglycemic therapy and clinical outcomes after acute myocardial infarction in older patients with diabetes Circ. Cardiovasc. Qual. Outcomes, 3 (3) (2010), pp. 236-242

[28] D.M. Mann, D. Ponieman, H. Leventhal, E.A. Halm Predictors of adherence to diabetes medications: the role of disease and medication beliefs J. Behav. Med., 32 (3) (2009), pp. 278-284

[29] C.W. Hunt, J.S. Grant, D.A. Pritchard An empirical study of self-efficacy and social support in diabetes self-management: implications for home healthcare nurses Home Healthc. Nurse, 30 (4) (2012), pp. 255-262

[30] K.M. Keogh, S.M. Smith, P. White, S. McGilloway, A. Kelly, J. Gibney et al. Psychological family intervention for poorly controlled type 2 diabetes Am. J. Manag. Care, 17 (2) (2011), pp. 105-113

[31] M.C. Schokker, T.P. Links, J. Bouma, J.C. Keers, R. Sanderman, B.H. Wolffenbuttel et al. The role of overprotection by the partner in coping with diabetes: a moderated mediation model Psychol. Health, 26 (1) (2011), pp. 95-111 
Kasteleyn, M.J., Gorter, K.J., Puffelen, A.L. van, Heijmans, M., Vos, R.C., Jansen, H., Rutten, G.E.H.M. What follow-up care and self-management support do patients with type 2 diabetes want after their first acute coronary event? A qualitative study. Primary Care Diabetes: 2014 8(3), 195-206

\section{TABLES AND FIGURES}
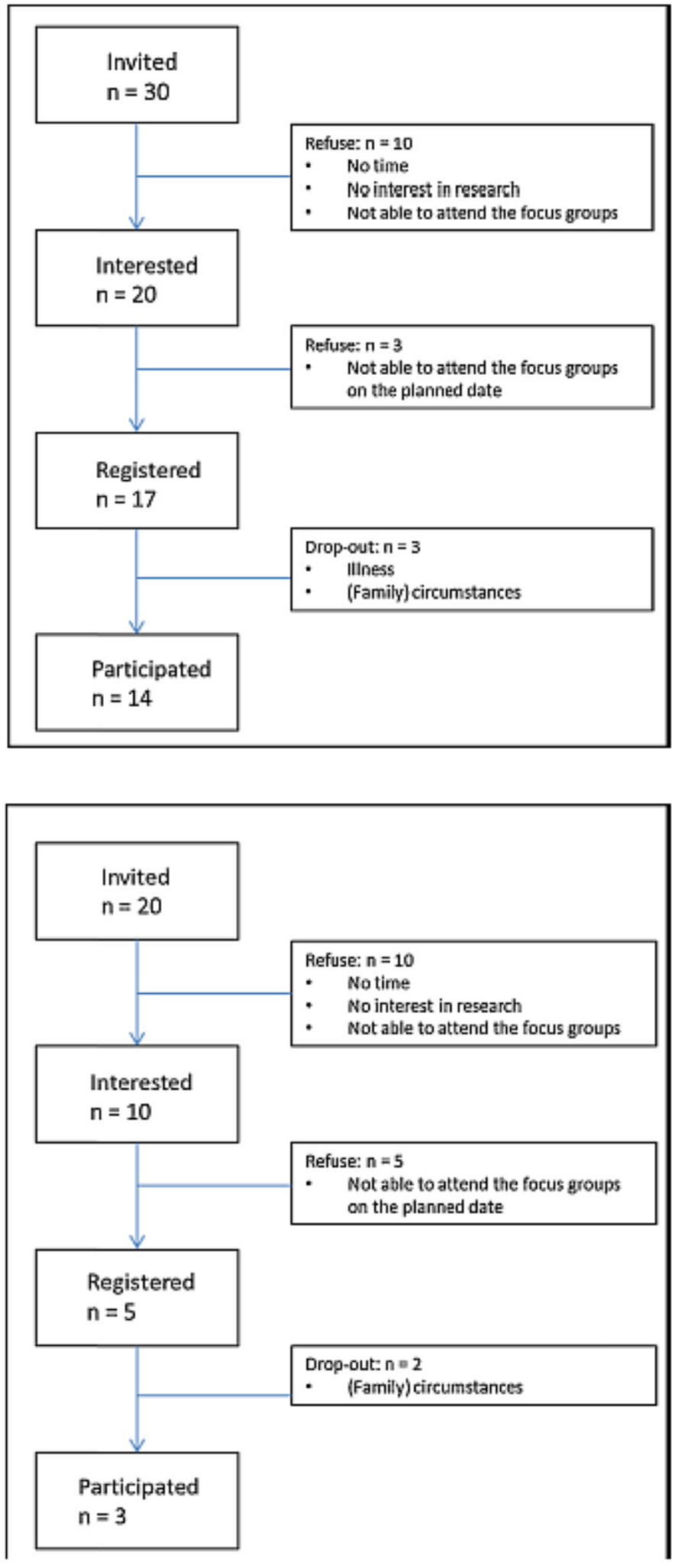

Fig. 1 - Flowchart inclusion patients (upper chart) and partners (lower chart). 
Kasteleyn, M.J., Gorter, K.J., Puffelen, A.L. van, Heijmans, M., Vos, R.C., Jansen, H., Rutten, G.E.H.M. What follow-up care and self-management support do patients with type 2 diabetes want after their first acute coronary event? A qualitative study. Primary Care Diabetes: 2014 8(3), 195-206

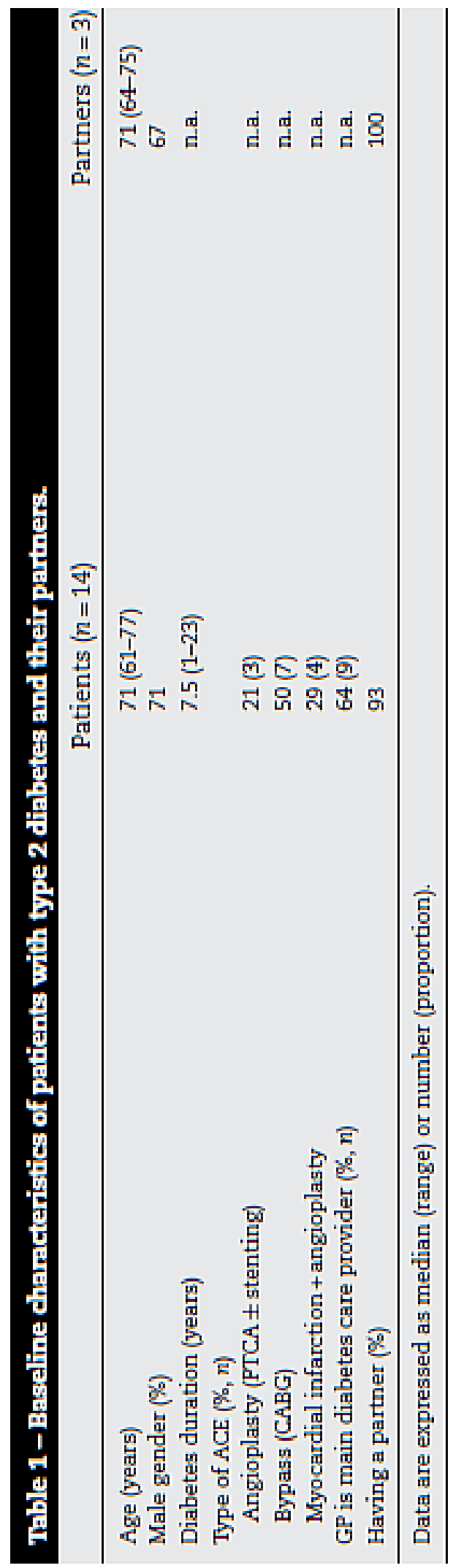


Kasteleyn, M.J., Gorter, K.J., Puffelen, A.L. van, Heijmans, M., Vos, R.C., Jansen, H., Rutten, G.E.H.M. What follow-up care and self-management support do patients with type 2 diabetes want after their first acute coronary event? A qualitative study. Primary Care Diabetes: 2014

8(3), 195-206

\section{Table 2 - Quotes from the focus group participants.}

1. Impact of ACE and Type $2 \mathrm{DM}$

1.1. 'After the diagnosis diabetes, I fell into a black hole. I didn't know what to do at all. That improved over two years. When I was finally able to cope with my diabetes, it was followed by a heart problem. Somehow, because of the diabetes, you are more prepared for a heart problem.' (male, 69 years)

1.2. 'I have too much 'ands' in my diseases, ánd artrosis, ánd high blood pressure, ánd diabetes, ánd heart. And then you are going to set priorities. I let my diabetes slip.' (male, 69 years)

2. General information on Type $2 \mathrm{DM}$ and ACE

2.1. 'I think there is enough information available on diabetes, and enough information on heart problems, but not on the combination of these two.' (male, 77years)

2.2. 'I haven't got enough information. I would have liked to attend an education day. It was a mystery for me.' (partner, male, 75 years)

2.3. 'You said that diabetes is a risk factor for heart problems. We never knew that. They never told us.' (Partner, female, 64 years)

\section{Physical exercise}

3.1. 'I have received information about the angioplasty procedure but they haven't told me to 'go exercise' or 'go do this' or 'build it up' or something. So I did it myself.' (female, 71 years)

3.2. 'This is a big problem for me. I used to sport a lot. The cardiologist told me 'You should do whatever feels good to you, that's alright'. And at the heart rehabilitation they want everybody to do the same level of exercise. But for me that was too easy.' (male, 61 years)

3.3. 'Unfortunately, it took a long time before the heart revalidation group was started. He had to wait several weeks.' (partner, fermale, 64 years)

\section{Sexuality}

4.1. 'I was allowed to do anything that felt all right for me; for me that was clear.' (male, 61 years)

\section{Nutrition/diet}

5.1. 'For me, combining the diet for diabetes and the heart is going fairly well. I also have a leaflet which is very useful.' (male, 61 years)

\section{Medication}

6.1. 'I have to say, I attend two different clinics. And sometimes I received two different stories about the diabetes, about the tablets and side-effects.' (male, 69 years)

6.2. 'From the hospital I received a folder in which all types of drugs are described, including the intended effects and the possible side effects. I appreciated that very much.' (female, 72 years)

\section{Medical professionals}

7.1. 'At that moment, it was not clear to me for which problem I should attend which doctor. So I called a doctor and then the assistant told me 'you are at the wrong address.' (male, 66 years)

7.2. 'And then I had an appointment with the GP, but he told me he hasn't got enough time for me. The GP told me I should make a double appointment Well, then I do not want it anymore, and I thought, "never mind." (male, 64years)

\section{Partner}

8.1. 'We almost had arguments about it, because he wanted to go for a little trip around the block on his bicycle and thought that would be all right. And I said 'Don't do that, you don't know if you are allowed to do so.' (partner, female, 64 years)

8.2. 'As a partner, you always depend on the information your husband or wife gives you. Sometimes they will explain it to you in their own advantage.' (partner, female, 64 years)

9. Patients' perspectives on self-management support

9.1. 'If there had been a nurse, I would have liked that, yes. Then I would have thought, 'Look, they do care. Someone understands me.' (female, 71 years)

9.2. 'For me, personally, they don't need to visit me at home, but for my wife they do, because she is more concerned than I am.' (male, 64 years)

9.3. 'For me it would be like a kind of open intake. Where they ask you 'what problems or situations do you encounter?' And if you do this in your home, which means that the partner should be there too, you will receive more information than talking to the patient alone.' (male, 61years) 
Kasteleyn, M.J., Gorter, K.J., Puffelen, A.L. van, Heijmans, M., Vos, R.C., Jansen, H., Rutten, G.E.H.M. What follow-up care and self-management support do patients with type 2 diabetes want after their first acute coronary event? A qualitative study. Primary Care Diabetes: 2014 8(3), 195-206

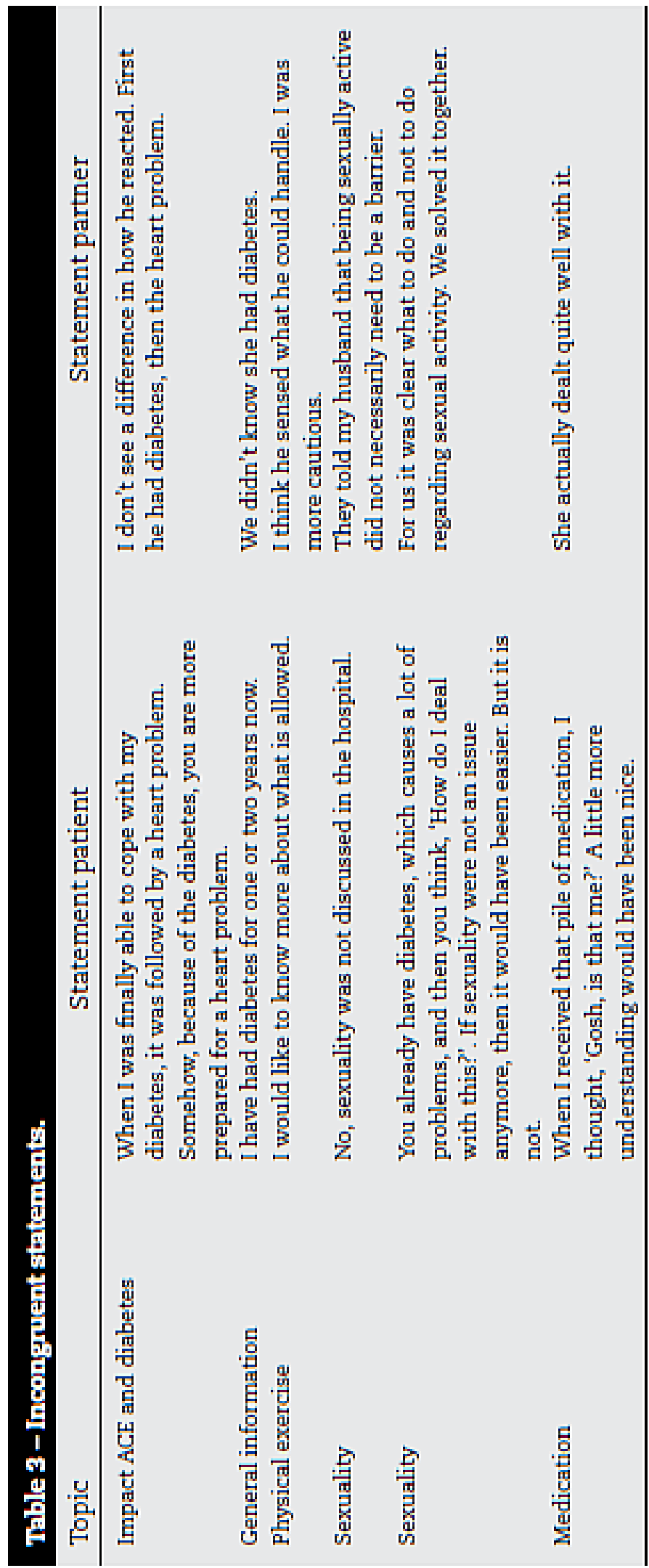

